\title{
Metabolic engineering of Zymomonas mobilis for 2,3-butanediol production from lignocellulosic biomass sugars
}

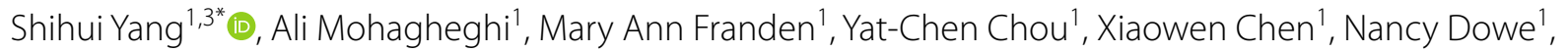
Michael E. Himmel ${ }^{2}$ and Min Zhang ${ }^{1^{*}}$

\begin{abstract}
Background: To develop pathways for advanced biofuel production, and to understand the impact of host metabolism and environmental conditions on heterologous pathway engineering for economic advanced biofuels production from biomass, we seek to redirect the carbon flow of the model ethanologen Zymomonas mobilis to produce desirable hydrocarbon intermediate 2,3-butanediol (2,3-BDO). 2,3-BDO is a bulk chemical building block, and can be upgraded in high yields to gasoline, diesel, and jet fuel.

Results: 2,3-BDO biosynthesis pathways from various bacterial species were examined, which include three genes encoding acetolactate synthase, acetolactate decarboxylase, and butanediol dehydrogenase. Bioinformatics analysis was carried out to pinpoint potential bottlenecks for high 2,3-BDO production. Different combinations of 2,3-BDO biosynthesis metabolic pathways using genes from different bacterial species have been constructed. Our results demonstrated that carbon flux can be deviated from ethanol production into 2,3-BDO biosynthesis, and all three heterologous genes are essential to efficiently redirect pyruvate from ethanol production for high 2,3-BDO production in Z. mobilis. The down-selection of best gene combinations up to now enabled Z. mobilis to reach the 2,3-BDO production of more than $10 \mathrm{~g} / \mathrm{L}$ from glucose and xylose, as well as mixed C6/C5 sugar streams derived from the deacetylation and mechanical refining process.

Conclusions: This study confirms the value of integrating bioinformatics analysis and systems biology data during metabolic engineering endeavors, provides guidance for value-added chemical production in Z. mobilis, and reveals the interactions between host metabolism, oxygen levels, and a heterologous 2,3-BDO biosynthesis pathway. Taken together, this work provides guidance for future metabolic engineering efforts aimed at boosting 2,3-BDO titer anaerobically.
\end{abstract}

Keywords: Zymomonas mobilis, 2,3-Butanediol, Metabolic engineering, Omics, Redox balance, Advanced biofuel, Fermentation, Respiration chain

\section{Background}

With the thriving interest today in sustainable and secure domestic advanced hydrocarbon production, extensive research has been conducted on microorganisms that naturally produce high titers of intermediates for drop-in fuels upgrading. A number of microorganisms have been

\footnotetext{
*Correspondence: shhyoung@hotmail.com; Min.Zhang@nrel.gov

${ }^{1}$ National Bioenergy Center, National Renewable Energy Laboratory, Golden 80401, USA

Full list of author information is available at the end of the article
}

recently engineered to produce hydrocarbon or hydrocarbon intermediates. However, there are only a few reports about the development of commercially viable strains for the production of advanced hydrocarbon or hydrocarbon intermediates. 2,3-butanediol (2,3-BDO) is an economically important platform bulk chemical that can be used in a variety of chemical feedstocks, liquid fuels, and biosynthetic building blocks, such as synthetic rubber, solvents, and food additives. For example, dehydration can convert 2,3-BDO into methyl ethyl ketone, 
which can be used as a liquid fuel additive; and 2,3-BDO can also be deoxydehydrated into 1,3-butadiene, which is a critical building block for synthetic rubber. 1,3-butadiene can also be oligomerized in high yields to gasoline, diesel, and jet fuel [1-11]. 2,3-BDO can be produced efficiently by fermentation with microorganisms, such as Klebsiella sp., Enterobacter sp., Serratia sp., Bacillus sp., and the yeast, Saccharomyces cerevisiae [1-5, 12-16]. The 2,3-BDO biosynthesis pathway in these microorganisms utilizes three enzymes: acetolactate synthase (Als), acetolactate decarboxylase (AldC), and butanediol dehydrogenase (Bdh), which convert, sequentially, pyruvate to $\alpha$-acetolactate, acetoin, and then 2,3-butanediol. High 2,3-BDO titer has been reported in native and engineered microorganisms, especially under fedbatch fermentation conditions. This body of work has been reported and reviewed extensively with excellent summaries on 2,3-BDO production pathways, microorganisms, pathway engineering strategies, operation conditions, and downstream processing [1-4]. For example, microbial 2,3-BDO production using different bacterial species, substrates, and fermentation methods has been summarized by Ji et al. [3]. Work to demonstrate heterologous 2,3-BDO production in the heterologous hosts $E$. coli [17-21] and cyanobacteria Synechococcus elongatus PCC 7942 (about $120 \mathrm{mg} / \mathrm{L}$ ) [22, 23] as well as pure 2,3BDO stereoisomer production in E. coli [24-28] has also been reported. However, most of these strains are aerobic or classified as risk group 2 microorganisms, which are not suitable for commercial production due to EPA biosafety regulations. The cost of aeration at large scale is also widely considered a problem for economic production. Moreover, most native microorganisms produce mixtures of three 2,3-BDO stereoisomers and, thus, metabolic engineering efforts are needed for production of pure stereoisomers [29-33].

Zymomonas mobilis is well known for both its high specific glucose uptake rate and rapid catabolism, and is engineered to metabolize all major biomass sugars [3438]. Improved Z. mobilis strains developed by DuPont and NREL have been used for commercial-scale cellulosic bioethanol production in DuPont's cellulosic ethanol plant at Nevada, IA, which is currently licensed to China and Macedonia. A novel deacetylation and discrefining (DDR) process, also known as deacetylation and mechanical refining (DMR), followed by enzymatic hydrolysis, has been shown to result in low toxicity, high concentration mixed sugar syrups that are capable of producing high product titers in the biological upgrading of these sugars $[39,40]$. Superior fermentation performance using Z. mobilis for conversion of DDR or DMR sugar streams to ethanol has been demonstrated [41, 42]. In addition, different approaches have been applied to develop the robust $Z$. mobilis $8 \mathrm{~b}$ strains to enhance ethanol productivity in the presence of pretreatment inhibitors. These approaches include classical chemical mutagenesis and adaptation, transposon mutagenesis, as well as the forward genetics approach that resulted in the development of various robust strains [36, 43-49], such as the hydrolysate-tolerant mutant 8b-OEL22C (22C) [44]. To broaden the antibiotics availability for further metabolic engineering of commercially relevant $Z$. mobilis strains, a new $Z$. mobilis strain, 9C, was generated from its parental strain, 8b [37], with both tetracycline and chloramphenicol antibiotics markers removed. We found that the performance of strain 9C in different sugar sources is same as that of $8 \mathrm{~b}$ (Unpublished data).

Since the genome sequence and functional re-annotation were reported $[50,51]$, a substantial library of systems biology data as well as several metabolic modeling studies have been accumulated in recent years to better understand the inhibitor tolerance mechanisms of $Z$. mobilis [52-66]. These inhibitors include the endproduct ethanol and toxic compounds from pretreated biomass, such as acetate, furfural, and soluble phenolic compounds. This information laid a solid foundation for future systems biology studies and provided data for omics-guided metabolic engineering practices in $Z$. mobilis.

This work is focused on developing a novel process for anaerobic 2,3-BDO production from biomass derived mixed C5/C6 sugar streams. We aim to take advantage of Z. mobilis' capabilities for rapid and efficient utilization of biomass-derived mixed sugar streams and redirect the carbon flux from ethanol to heterologous 2,3-BDO production to avoid the problem of mixed stereoisomers in native strains for pure stereoisomer production. Once sufficiently understood, we will work to develop novel pathways for advanced biological upgrading of sugars to high carbon efficiency intermediates amenable to separations and catalytic upgrading to hydrocarbon fuels.

\section{Results}

Investigate 2,3-BDO toxicity to $Z$. mobilis

First, we examined the feasibility of engineering $Z$. mobilis for high 2,3-BDO production by investigating the toxicity of 2,3-BDO to Z. mobilis in RMG2 medium at $30{ }^{\circ} \mathrm{C}$ using the Bioscreen $C$ high-throughput growth measurement instrument. Our result showed that $Z$. mobilis tolerates higher concentration of 2,3-BDO than that of ethanol (Fig. 1). The growth rate decreased to $0.3 \mathrm{~h}^{-1}$ when about $80 \mathrm{~g} / \mathrm{L} 2,3-\mathrm{BDO}$ was supplemented to the growth medium, whereas less than $45 \mathrm{~g} / \mathrm{L}$ ethanol was needed to slow the growth of $Z$. mobilis to similar growth rate. When $80 \mathrm{~g} / \mathrm{L}$ ethanol was added into the medium, the growth rate of $Z$. mobilis was only about one-third 


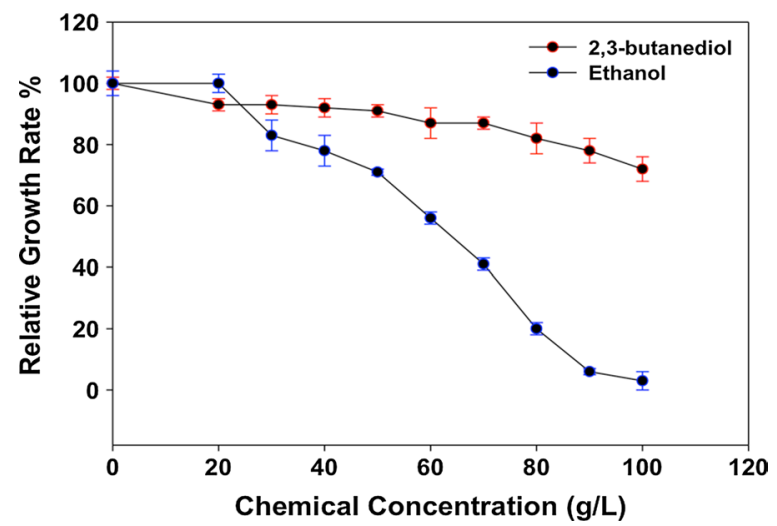

Fig. 1 The impact of meso-2,3-BDO and ethanol supplementation on growth of Z. mobilis in RMG medium at $30^{\circ} \mathrm{C}$ using Bioscreen C. Relative growth rate (\%) is the percentage of growth rate with chemical supplementation compared to control without

of that observed for the same amount of 2,3-BDO added (Fig. 1). Even when the concentration of 2,3-BDO was increased to $100 \mathrm{~g} / \mathrm{L}$, the growth rate of $Z$. mobilis decreased to $0.25 \mathrm{~h}^{-1}$, but it was still more than half of the control without 2,3-BDO supplementation. The low toxicity of 2,3-BDO to $Z$. mobilis indicates that $Z$. mobilis has a strong potential for achieving high titers, rate, and yields for 2,3-BDO production.

\section{Construct a minimized vector for pathway engineering}

To maximize the pathway engineering potential allowing for large plasmid constructions such as the three-gene 2,3-BDO pathway in this study, a minimized shuttle vector was constructed. The resultant plasmid, pEZ15Asp (pEZ), contains only the essential elements: origins of replication for both $E$. coli and $Z$. mobilis, an antibiotic marker of spectinomycin resistance gene $a d d A$, and multiple cloning sites and, therefore, significantly reduces its size when compared with the original plasmid (from 8 to $3 \mathrm{~kb})$. Multiple cloning sites include restriction enzyme sites of EcoRI, XbaI, SpeI and PstI for the Biobrick cloning strategy [67] enabling pathway engineering (see Table 1 and S1 A for plasmid information and sequence).

\section{Identify and select 2,3-BDO pathway genes} for heterologous 2,3-BDO pathway construction

Literature related to 2,3-BDO production was reviewed, which includes the analysis of native 2,3-BDO biosynthesis pathways in addition to the expression of heterologous enzymes for $2,3-\mathrm{BDO}$ production $[1,2,5,10$, $12,13,15,16,19,20,23,25,27,68,69]$. The 2,3-BDO pathways from Bacillus licheniformis and Enterobacter cloacae have been successfully expressed in E. coli [13, $16,30,33,70,71]$, suggesting the feasibility of $2,3-\mathrm{BDO}$ production in Z. mobilis. The gene combination resulting in high 2,3-BDO yields and experimental methods reported in these papers laid a solid foundation for our work. We then compiled a list of 2,3-BDO pathway genes and the promising source microorganisms. After eliminating pathogenic organisms from our list, we chose two bacterial species, B. licheniformis and E. cloacae, for the source of our three-gene 2,3-BDO biosynthesis pathway reported here.

The sequences (nucleotide and protein) of three genes (als, aldC, and $b d h$ ) were extracted and BLASTed against the $Z$. mobilis genome including our recently updated native plasmid sequences. BLAST results indicate that Bdh only has homologs with low similarity in $Z$. mobilis; therefore, heterologous $b d h$ genes were included in our pathway engineering strategy. In addition, the reaction that Bdh catalyzes is a reversible reaction, with some enzymes preferring NADPH as a cofactor. Bdh enzymes preferring the reduction reaction from acetoin to butanediol using $\mathrm{NADH}$ were selected for minimizing redox imbalance and for achieving high 2,3-BDO yield.

Additional BLAST results for the other two enzymes required for 2,3-BDO production indicate that $Z$. mobilis possesses three homologs to Als, of which ZMO1139/ ZMO1140 (IlvB/C) may form a complex contributing to amino acid biosynthesis. The homolog ZMO0687 has a high similarity to the catabolic enzyme, Als. The high similarity between Als, IlvB (ZMO1139), and Pdc (ZMO1360) based on protein sequence alignment indicates that there could potentially be competition among them for substrate (pyruvate) binding and utilization. Additionally, since Pdc in Z. mobilis is required for ethanol production, providing energy, and maintaining redox balance for robust cellular growth, strategies to shift the carbon flux toward 2,3-BDO production are required. This can be accomplished by inhibiting $p d c$ gene expression and Pdc enzyme activity or by enhancing the performance of the heterologous Als enzyme.

Gene expression patterns of the Als homologous gene in $Z$. mobilis were subsequently examined using public and in-house transcriptomic datasets of microarray and next-generation sequencing (NGS)-based RNA-Seq. The result indicated that the als gene homologs are abundantly expressed under different conditions, and that ZMO0687 is also differentially expressed in cells grown from media containing different carbon sources (e.g., downregulated in xylose medium compared to glucose). Furthermore, ZMO1141, which catalyzes the formation of (R)-2,3-dihydroxy-3-methylbutanoate from $\alpha$-acetolactate (hereafter referred to as acetolactate) for valine, isoleucine, and leucine biosynthesis, has an abundant transcript level of average $\log _{2}$-based microarray intensity result of 13.78 compared to 14.69 for $p d c$ 
Table 1 The source and components of the 2,3-BDO pathway constructed and the corresponding 2,3-BDO titer (g/L) after 24-h post-inoculation in Z. mobilis $8 \mathrm{~b}$

\begin{tabular}{|c|c|c|}
\hline Strain or plasmid & Characteristic(s) & Source or reference \\
\hline \multicolumn{3}{|l|}{ Plasmids } \\
\hline pEZ15Asp (pEZ) & Shuttle vector contains Z. mobilis origin and E. coli origin p15A; Sp ${ }^{R}$; Biobrick-compatible & This work \\
\hline pEZ-GS6 & $\begin{array}{l}\text { pEZ containing construct GS6: aldC and bdh genes from E. cloacae driven by its native promoter [PEC_ } \\
\text { (ALDC-BDH)] }\end{array}$ & This work \\
\hline pEZ-GS2 & $\begin{array}{l}\text { pEZ containing construct GS2: codon-optimized aldC and bdh genes from E. cloacae driven by Pgap pro- } \\
\text { moter [GS2: Pgap_(ALDC-BDH) }\end{array}$ & This work \\
\hline $\mathrm{pEZ}-\mathrm{BC} 3$ & $\begin{array}{l}\text { pEZ containing construct BC3: codon-optimized aldC and bdh genes from } B \text {. licheniformis driven by Pgap } \\
\text { and Peno promoter respectively [(Pgap_ALDC)-(Peno_BDH)] }\end{array}$ & This work \\
\hline $\mathrm{pEZ}-\mathrm{BC} 4$ & $\begin{array}{l}\text { pEZ containing construct BC4: alS gene from E. cloacae driven by its native promoter (PEc_ALSecwt) and } \\
\text { GS6 construct [(PEC_ALSecwt)-GS6] }\end{array}$ & This work \\
\hline pEZ-BC5 & $\begin{array}{l}\text { pEZ containing construct BC5: codon-optimized alS gene from E. cloacae driven by Peno (Peno_ALSecopt) } \\
\text { and GS2 construct [(Peno_ALSecopt)-GS2] }\end{array}$ & This work \\
\hline pEZ-BC9 & $\begin{array}{l}\text { pEZ containing construct BC9: codon-optimized alS gene from B. licheniformis driven by inducible promoter } \\
\text { Ptet (Ptet_BIAls) and GS2 construct [(Ptet-BIAls)-GS2] }\end{array}$ & This work \\
\hline $\mathrm{pEZ}-\mathrm{BC} 10$ & $\begin{array}{l}\text { pEZ containing construct BC10: codon-optimized als gene from B. subtilis driven by inducible promoter Ptet } \\
\text { (Ptet-BsAls1) and GS2 construct [(Ptet-BsAls1)-GS2] }\end{array}$ & This work \\
\hline pEZ-BC11 & $\begin{array}{l}\text { pEZ containing construct BC11: 2nd version of codon-optimized alS gene from B. subtilis driven by inducible } \\
\text { promoter Ptet (Ptet-BsAlss) and GS2 construct [(Ptet-BsAls2)-GS2] }\end{array}$ & This work \\
\hline \multicolumn{3}{|l|}{ Bacterial strains } \\
\hline E. coli C2925 & $\begin{array}{l}\text { ara-14 leuB6 fhuA31 lacY1 tsx78 glnV44 galK2 galT22 mcrA dem-6 hisG4 rfbD1 R(zgb210::Tn10) Tc }{ }^{\mathrm{S}} \text { endA1 rspL136 } \\
\left(\text { (Str }^{\mathrm{R}}\right) \text { dam13::Tn9 }\left(\mathrm{Cm}^{\mathrm{R}}\right) \text { xylA-5 mtl-1 thi-1 mcrB1 hsdR2 }\end{array}$ & NEB \\
\hline $8 b$ & Engineered Z. mobilis subsp. ZM4 strain for xylose utilization, $T c^{R} C^{R}$ & [37] \\
\hline $9 \mathrm{C}$ & $8 \mathrm{~b}$ derivative with tetracycline and chloramphenicol antibiotics markers cured, $T c^{5} \mathrm{Cm}^{\mathrm{S}}$ & Lab stock \\
\hline $22 \mathrm{C}$ & $8 \mathrm{~b}$ derivate with enhanced corn stover hydrolysate tolerance, $T c^{R} C^{R}$ & {$[44]$} \\
\hline $8 b-p E Z$ & Z. mobilis 8b containing control plasmid pEZ & This work \\
\hline $8 b-G S 2$ & Z. mobilis $8 b$ containing plasmid pEZ-GS2 & This work \\
\hline $8 b-G S 6$ & Z. mobilis $8 \mathrm{~b}$ containing plasmid pEZ-GS6 & This work \\
\hline $8 b-B C 3$ & Z. mobilis $8 b$ containing plasmid pEZ-BC3 & This work \\
\hline $8 b-B C 4$ & Z. mobilis $8 b$ containing plasmid pEZ-BC4 & This work \\
\hline $8 b-B C 5$ & Z. mobilis $8 b$ containing plasmid pEZ-BC5 & This work \\
\hline $22 C-p E Z$ & Z. mobilis $22 \mathrm{C}$ containing control plasmid pEZ & This work \\
\hline $22 C-B C 5$ & Z. mobilis $22 \mathrm{C}$ containing plasmid pEZ-BC5 & This work \\
\hline $9 \mathrm{C}-\mathrm{BC5}$ & Z. mobilis $9 \mathrm{C}$ containing plasmid pEZ-BC5 & This work \\
\hline $9 \mathrm{C}-\mathrm{BC} 9$ & Z. mobilis 9 C containing plasmid pEZ-BC9 & This work \\
\hline $9 C-B C 10$ & Z. mobilis $9 \mathrm{C}$ containing plasmid pEZ-BC10 & This work \\
\hline $9 \mathrm{C}-\mathrm{BC} 11$ & Z. mobilis $9 \mathrm{C}$ containing plasmid pEZ-BC11 & This work \\
\hline
\end{tabular}

Culture condition: $40 \mathrm{~mL}$ RMG8 in $125-\mathrm{mL}$ flask, $33^{\circ} \mathrm{C}, 120 \mathrm{rpm}$

EC E. cloacea; BL B. lincheniformis. $S p^{R}$ spectinomycin resistance; $T c^{R}$ tetracycline resistance; $C m^{R}$ chloramphenicol resistance; $T c^{S}$ tetracycline sensitive; $C m^{R}$ chloramphenicol sensitive

(Additional file 1: Table S1B); therefore, the acetolactate decarboxylase (AldC) to be engineered should have a strong affinity for the substrate acetolactate to compete with ZMO1141, thus ensuring carbon flux toward acetoin and 2,3-BDO.

\section{Construct heterologous 2,3-BDO pathway in Z. mobilis and optimize flask fermentation conditions}

The gene expression cassettes containing the sequences of three codon-optimized 2,3-BDO pathway genes (als, aldC, and bdh) from B. licheniformis and E. cloacae as well as wild-type version from $E$. cloacae were then designed and synthesized (Table 2). As discussed above, Z. mobilis has three als gene homologs, but does not have the ald $C$ and $b d h$ genes needed for 2,3-BDO production. Additionally, since $Z$. mobilis Pdc is a very abundant and efficient enzyme with low $\mathrm{Km}(<0.31 \mathrm{mM})$ and high $k_{\text {cat }}$ ( $>1001 / \mathrm{s}$ ), a strong als gene may be needed to divert carbon flux from ethanol production to 2,3-BDO. We, therefore, constructed several pathways with either two genes (aldC and $b d h$ ) or three genes (als, aldC, and $b d h$ ). These genes were assembled using the Biobrick-based 
Table 2 The source and components of the 2,3-BDO pathway constructed and the corresponding 2,3-BDO titer (g/L) after 24-h post-inoculation in Z. mobilis $8 \mathbf{b}$

\begin{tabular}{lllllll}
\hline Strain & Plasmid & Promoter & Species & Enzymes & Codon optimization & BDO (g/L) \\
\hline $8 \mathrm{~b}-\mathrm{GS6}$ & $\mathrm{pEZ-GS6}$ & Wild-type & E. cloacea & AldC, Bdh & No & 1.42 \\
$8 \mathrm{~b}-\mathrm{GS} 2$ & $\mathrm{pEZ-GS2}$ & Pgap & E. cloacea & AldC, Bdh & Yes & 3.69 \\
$8 \mathrm{~b}-\mathrm{BC3}$ & $\mathrm{pEZ-BC3}$ & Pgap, Peno & B. lincheniformis & AldC, Bdh & Yes & 2.88 \\
$8 \mathrm{~b}-\mathrm{BC} 4$ & $\mathrm{pEZ-BC4}$ & Wild-type & E. cloacea & Als, AldC, Bdh & No & 1.9 \\
$8 \mathrm{~b}-\mathrm{BC5}$ & $\mathrm{pEZ-BC5}$ & Peno, Pgap & E. cloacea & Als, AldC, Bdh & Yes & 5.0 \\
\hline
\end{tabular}

Culture condition: $40 \mathrm{~mL}$ RMG8 in $125-\mathrm{mL}$ flask, $33^{\circ} \mathrm{C}, 120 \mathrm{rpm}$

EC E. cloacea; BL B. licheniformis

metabolic pathway engineering strategy and cloned into the minimized shuttle vector pEZ (Table 1). The results indicated that the three-gene pathways produced more 2,3-BDO than did the two-gene pathways (Table 2; Fig. 2).

Three constructs (vector control pEZ, two-gene pathway plasmid pEZ-GS2, and three-gene pathway plasmid pEZ-BC5) were further compared in two strain backgrounds of $8 \mathrm{~b}$ or $22 \mathrm{C}$ (Table 1). The introduction of heterologous als gene significantly increased 2,3-BDO production by shifting carbon flow away from ethanol production (Fig. 2).

Clearly 2,3-BDO production could be significantly enhanced if the native ethanol production pathway was impeded by knocking out key ethanol production genes of pyruvate decarboxylase $(p d c)$ and alcohol dehydrogenase $(a d h)$, which has been demonstrated in $S$. cerevisiae that 2,3-BDO production increased in Pdc-deficient mutants [5, 7-10]. We have attempted to knock out or knock down the $p d c$ gene to divert carbon to 2,3-BDO production without success, a result consistent with

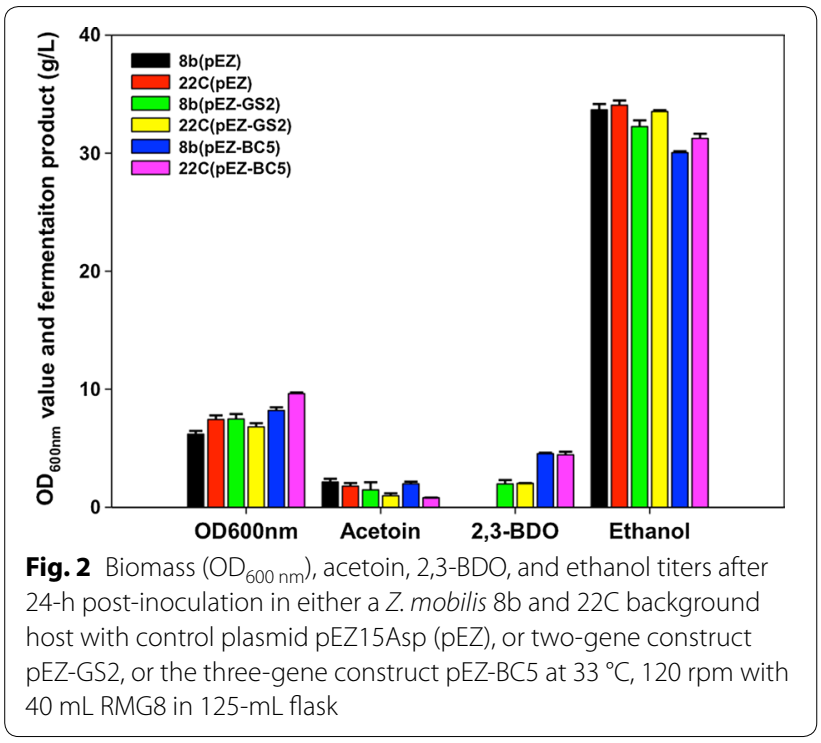

previous reports that $p d c$ is essential for native Z. mobilis and cannot be completely knocked out. Furthermore, our efforts testing $p d c$ knockout in 2,3-BDO production strains, such as $9 \mathrm{C}-\mathrm{BC} 5$ and $9 \mathrm{C}-\mathrm{BC} 11$, were also not successful. We will continue to work on blocking the route from pyruvate to ethanol to maximize the potential 2,3BDO titer with balanced redox using similar strategies as reported in yeast $[5,6,72-74]$.

To optimize the 2,3-BDO production, different flask fermentation conditions were first investigated using the three-gene pathway construct in the $22 \mathrm{C}$ background (22C-BC5) and using the empty vector $\mathrm{pEZ}$ as a negative control (Table 1; Fig. 3a). Results indicate that 2,3-BDO can be produced using mixed sugar conditions (glucose, or glucose and xylose), as well as from DMR-pretreated biomass (Fig. 3b). Growth conditions that varied the shaking speed and medium volume affecting oxygen dispersion impacted acetoin and 2,3-BDO production (Fig. 3b). For example, acetoin titers rose above $10 \mathrm{~g} / \mathrm{L}$ when the shaking speed was increased to $200 \mathrm{rpm}$ with $40 \mathrm{~mL}$ medium in the 125 - $\mathrm{mL}$ baffled flask (Fig. 3b).

\section{Optimize heterologous 2,3-BDO pathway to increase 2,3-BDO titer}

Initial 2,3-BDO engineering efforts in introducing heterologous ald $C$ and $b d h$ genes into $Z$. mobilis resulted in the 2,3-BDO production of about $3.7 \mathrm{~g} / \mathrm{L}$, which confirms that both ald $C$ and $b d h$ genes are required for 2,3-BDO production in Z. mobilis. Furthermore, the addition of a heterologous als gene from E. cloacae increased 2,3-BDO titers to about $5.0 \mathrm{~g} / \mathrm{L}$ (Table 2), which again upheld the assumption that an additional als gene may be needed to redirect carbon flux from ethanol production into 2,3-BDO to compete with the abundant and highly active $Z$. mobilis Pdc enzyme. Our data thus suggested that the bottleneck reactions to increase 2,3-BDO production could be acetolactate generation from pyruvate and 2,3-BDO production from acetoin. We hypothesize that stronger als and $b d h$ genes, or genes encoding more active enzymes, will boost BDO production. 

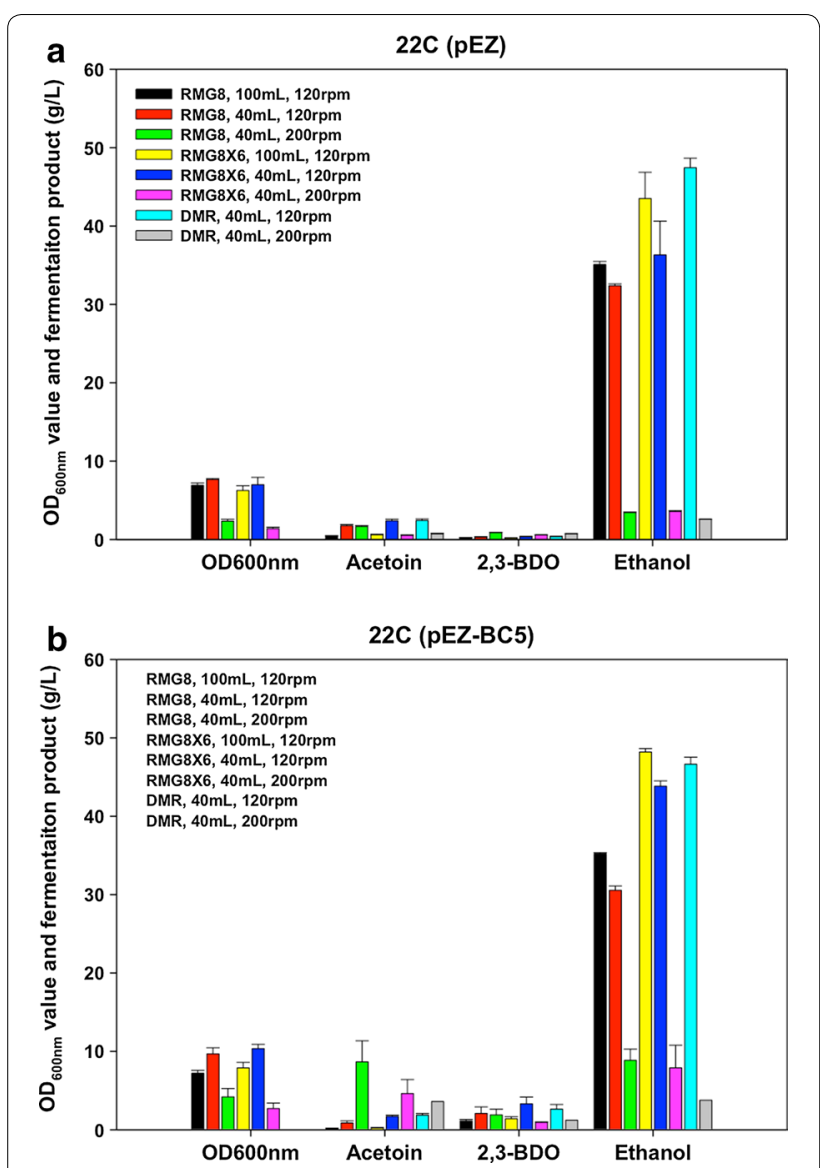

Fig. 3 Biomass $\left(\mathrm{OD}_{600 \mathrm{~nm}}\right)$, acetoin, 2,3-BDO, and ethanol titers after 24-h post-inoculation under different fermentation conditions which varied shaking speed (120 or $200 \mathrm{rpm}$ ), volume (100 or $40 \mathrm{~mL}$ in 125-mL flask), and media (RMG8, RMG8X6, and DMR) for control strain $22 \mathrm{C}(\mathrm{pEZ})(\mathbf{a})$ and three-gene pathway construct Z. mobilis 22C-BC5 (b) at $33^{\circ} \mathrm{C}$

To ascertain whether other heterologous als genes with higher specific enzymatic activities than $E$. cloacae one as reported in E. coli [16] could improve carbon flux from ethanol production into 2,3-BDO, als genes from $B$. licheniformis (BlAls) and B. subtilis (BsAls) were synthesized and cloned. These included one codon-optimized BlAls gene and two versions of the BsAls genes (BsAls1 and BsAls2) with different codon optimization outputs using Genscript's codon optimization algorithm. The attempt to incorporate the als gene from $B$. lichenformis (BlAls) under control of the strong Peno promoter along with the expression of AldC and Bdh using the Z. mobilis Pgap strong promoter was unsuccessful. Besides the possibility of cell growth inhibition by the enzyme Als from $B$. licheniformis and B. subtilis, this could be due to the protein burden caused by strong heterologous pathway gene expression. About $50 \%$ of the proteins in Z. mobilis are involved in the glycolysis pathway [75]. This view is supported by a previous report that overexpression of plasmid-encoded protein led to the reduction of both glycolytic flux and growth rate due to protein burden [76]. Similarly, previous work also suggested that protein burden could be the reason for the negative effect observed for the isopropyl $\beta$-D-thiogalactoside (IPTG) induction of 2,3-BDO biosynthesis in a recombinant $E$. coli strain [26].

To test this speculation and avoid the potential metabolic burden caused by strong heterologous gene expression, the strong Peno promoter was tested along with the Ptet inducible promoter for the construction of additional three-gene pathway constructs. These constructs also included a common ald $C$ and $b d h$ gene operon from E. cloacae driven by a strong promoter Pgap [Pgap(EcALDC-BDH)]. In total, six new 3-gene constructs with different versions of als genes from $B$. lincheniformis or B. subtilis were generated (BsAls1, BsAls2, and BlAls that were either driven by the strong Peno promoter or by the inducible Ptet promoter).

These six constructs were then transformed into $Z$. mobilis 9C (an 8b derivative that is lacking tetracycline and chloramphenicol resistance markers). Our result is consistent with our hypothesis that the transformation efficiencies were very high for plasmid constructs with the inducible promoter Ptet without tetracycline induction, but no positive transformants were obtained for constructs using the strong Peno promoter. 2,3-BDO production of three strains containing the three-gene construct with als driven by Ptet (Table 1) was measured, and the 2,3-BDO titer increased from 5-6 to $10-13 \mathrm{~g} / \mathrm{L}$ (Table 3). In addition, it is apparent that the carbon was diverted from ethanol to 2,3-BDO production, considering the strong negative correlation between ethanol and BDO titers 3 days post-inoculation with an R-squared value of 0.98 (Table 3 ).

We further compared sugar consumption and 2,3-BDO production kinetics in glucose only or mixed sugars (glucose and xylose) with the new strain producing the highest 2,3-BDO titers, 9C-BC11 (Table 1). We found that this strain is stable, and 2,3-BDO titers were more than $13 \mathrm{~g} / \mathrm{L}$ when grown in RMG8 or RMG8X6 media (Fig. 4). Notably, the addition of xylose delayed the sugar utilization of glucose and xylose; as well as cellular growth (Fig. 4). Furthermore, xylose was not completely utilized even 5 days after inoculation (data not shown). However, the concentration of 2,3-BDO in the mixed sugar fermentation remained level in stationary phase when compared to cultures grown in glucose only. In this case, levels of 2,3-BDO decreased after growth, possibly because of the reverse activity of Bdh converting 2,3-BDO back to acetoin, since decreasing 2,3-BDO titers was accompanied by in acetoin concentration increase (Fig. 4a). 
Table 3 The source and components of the 2,3-BDO pathway constructed and the corresponding BDO titer 1 day postinoculation in Z. mobilis $9 \mathrm{C}$

\begin{tabular}{llllllcc}
\hline Strain & Plasmid & Promoter & als source & Enzymes & Acetoin (g/L) & BDO (g/L) & Ethanol (g/L) \\
\hline $9 C-B C 9$ & pEZ-BC9 & Ptet & B. licheniformis & Als, AldC, Bdh & $1.6 \pm 0.4$ & $10.8 \pm 1.1$ & $26.2 \pm 0.5$ \\
$9 C-B C 10$ & pEZ-BC10 & Ptet & B. subtilis & Als, AldC, Bdh & $1.1 \pm 0.5$ & $10.2 \pm 2.0$ & $27.4 \pm 1.6$ \\
$9 C-B C 11$ & pEZ-BC11 & Ptet & B. subtilis & Als, AldC, Bdh & $0.7 \pm 0.1$ & $13.3 \pm 0.7$ & $24.9 \pm 0.5$ \\
\hline
\end{tabular}

The promoter of als gene in these constructed is driven by inducible promoter Ptet. Culture condition: $40 \mathrm{~mL} \mathrm{RMG8} \mathrm{with} 200 \mu \mathrm{g} / \mathrm{mL}$ spectinomycin in 125 -mL flask, $33^{\circ} \mathrm{C}, 120 \mathrm{rpm}$. Four replicates each without tetracycline induction

\section{Investigate fermentation conditions on 2,3-BDO productions}

To further understand the impact of oxygen concentration on 2,3-BDO production and fermentation byproduct profiles as indicated by flask fermentation optimization (Fig. 3), Biostat-Q Plus fermenters (Sartorius Stedim North America Inc., Bohemia, NY) with oxygen control capability were used for our highest 2,3-BDO producing strain, 9C-BC11. As a control, shake flask fermentation was also conducted. Glucose is usually consumed within $20 \mathrm{~h}$ by the parental strain $9 \mathrm{C}$ under anaerobic conditions. Interestingly, the glucose utilization of $Z$. mobilis 9C-BC11 under anaerobic conditions with $\mathrm{N}_{2}$ purging was significantly reduced with only $3 \mathrm{~g} / \mathrm{L}$ glucose consumed and no discernible cellular growth after $22 \mathrm{~h}$ post-inoculation. In contrast, more than half of the glucose had been used under shake flask conditions, and nearly all glucose was consumed upon reaching the highest $\mathrm{OD}_{600 \mathrm{~nm}}$ value of 5.34 under microaerophilic condition of $1 \%$ dissolved oxygen (DO) (Fig. 5a). However, glucose utilization and cellular growth were significantly decreased when $10 \%$ DO was supplied. At 48-h postinoculation, there was still $34 \mathrm{~g} / \mathrm{L}$ glucose remaining in the media, compared to other conditions tested where all glucose had been consumed (Fig. 5a), and the glucose level and $\mathrm{OD}_{600 \mathrm{~nm}}$ values remained relatively steady out to $120 \mathrm{~h}$ post-inoculation (Additional file 1: Table S1C).

Under anaerobic conditions with nitrogen sparging, nearly all glucose was ultimately converted into ethanol, producing only $1.68 \mathrm{~g} / \mathrm{L} 2,3-\mathrm{BDO}$. Increasing oxygen deliveries from 0 to $1 \% \mathrm{DO}$, or $10 \% \mathrm{DO}$, decreased ethanol production dramatically (Fig. 5b), and is consistent with a previous report that aerobic growth reduces ethanol production [63]. Although both 2,3-BDO and acetoin levels increased under aerobic growth, titers of 2,3-BDO and acetoin were significantly higher in the $1 \%$ DO culture than in the $10 \%$ DO culture (Fig. 5b, c).

Besides the major end-products ethanol, acetoin, and 2,3-BDO, the production profiles of minor byproducts of acetate, lactate, and glycerol were also affected by the oxygen levels in these cultures. More acetate was produced under aerobic conditions resulting in less ethanol production as reported in the literature [63].
Furthermore, acetate production was significantly higher in the more aerobic conditions ( 1 or $10 \%$ DO supplementation) than in the microaerophilic conditions using flask fermentation or $\mathrm{N}_{2}$-supplemented anaerobic fermentation (Fig. 5d). Additionally, more lactate was produced under aerobic conditions than in anaerobic condition as well (Fig. 5d). We had previously shown that the expression levels of the lactate dehydrogenase gene ZMO1237 were more abundant under aerobic conditions [63], and the expression of another D-lactate dehydrogenase gene, ZMO0256, was upregulated in the ethanol-treated cells during stationary phase [57]. The host strain, Z. mobilis $9 \mathrm{C}$, used in this study, is a derivative of $Z$. mobilis $8 \mathrm{~b}$ in which the ZMO1237 gene was inactivated [37]. Therefore, ZMO1237 may play the major role in lactate production under aerobic conditions. However, another lactate dehydrogenase gene, ZMO0256, could also be activated under aerobic conditions for lactate production, when ZMO1237 is deactivated, as shown in this study (Fig. 5d).

Intriguingly, despite the observation that more glycerol was produced under aerobic conditions (i.e., 1 or $10 \%$ DO) than under anaerobic conditions with $\mathrm{N}_{2}$ purging, a higher amount of glycerol was produced in shake flask fermentations (see Fig. 5c). In Z. mobilis, only one NAD ${ }^{+}$ is regenerated from 2,3-BDO biosynthesis compared to two $\mathrm{NAD}^{+}$from ethanol fermentation. The increase of glycerol production for in shake flasks may be explained by the utilization of the glycerol pathway to maintain redox balance $\left(\mathrm{NAD}^{+}\right.$feedback) while also provides ATP to sustain cellular growth (Fig. 6).

The highest $2,3-\mathrm{BDO}$ yield $(0.16 \mathrm{~g} / \mathrm{g}$ glucose $)$ was achieved under shake flask fermentations and the highest ethanol yield $(0.44 \mathrm{~g} / \mathrm{g}$ glucose $)$ was obtained under anaerobic conditions using $\mathrm{N}_{2}$ purging (Additional file 1: Table S1C). As oxygen supplementation increased, acetoin yields also increased; however, these conditions also produced lower ethanol yields. In addition, the yields of all fermentation products (ethanol, lactate, glycerol, and acetate) were reduced with the increasing oxygen levels. For example, ethanol yields decreased from $0.46 \mathrm{~g} / \mathrm{g}$ glucose under anaerobic conditions to $0.15 \mathrm{~g} / \mathrm{g}$ glucose in the $10 \% \mathrm{DO}$ culture (Additional file 1: Table S1C). 

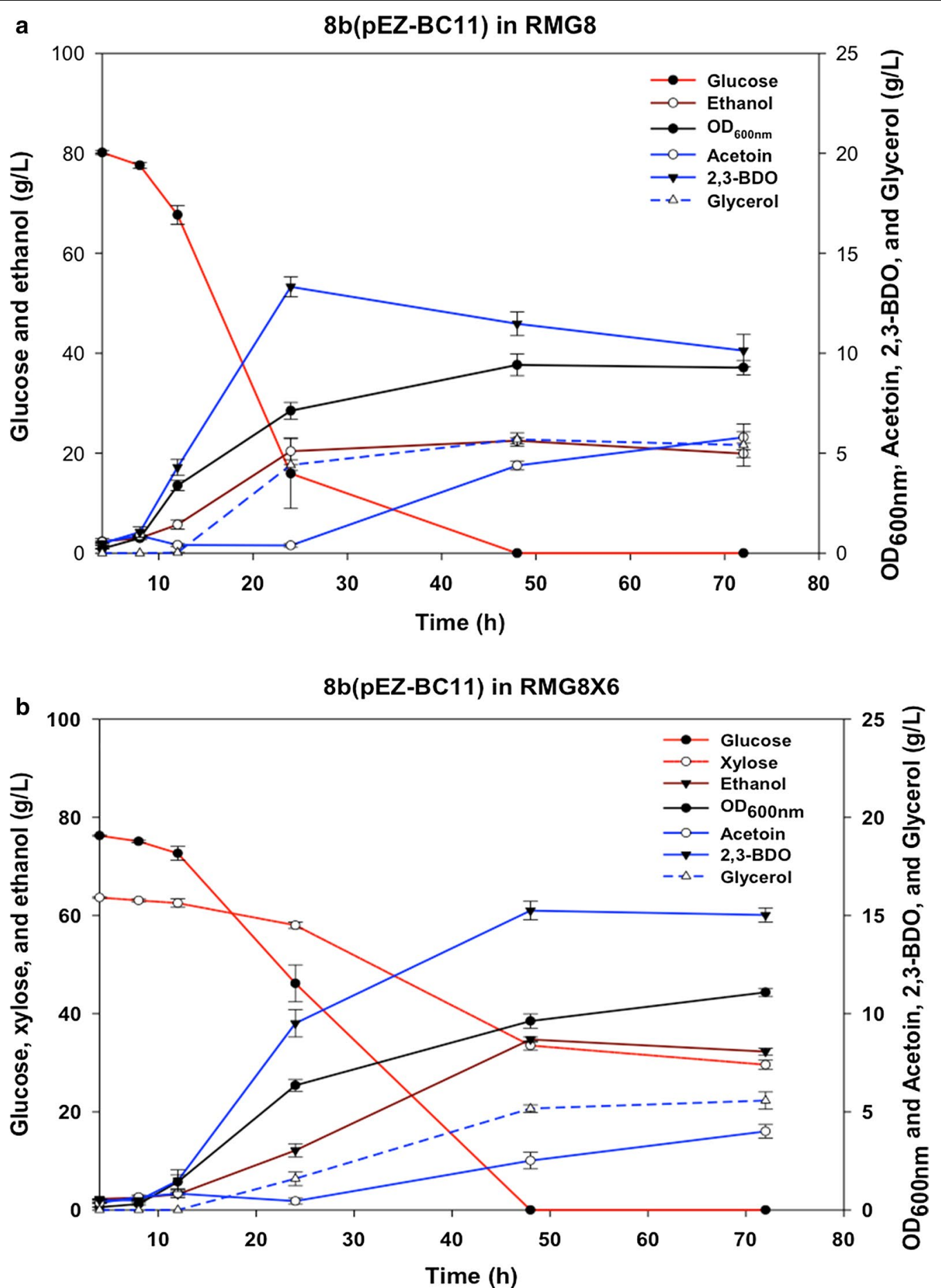

Fig. 4 Biomass $\left(\mathrm{OD}_{600 \mathrm{~nm}}\right)$, and concentrations of acetoin, 2,3-BDO, glycerol, ethanol as well as glucose and xylose for strain Z. mobilis $9 C-B C 11$ grown in pure sugar of RMG8 (a) or mixed sugar of RMG8X6 (b). Culture condition: $40 \mathrm{~mL}$ RMG8 or RMG8X6 with $200 \mu \mathrm{g} / \mathrm{mL}$ spectinomycin in 125$\mathrm{mL}$ flask, $33^{\circ} \mathrm{C}, 120 \mathrm{rpm}$. Three replicates each without tetracycline induction

Conversely, the ratios of the heterologous products, acetoin and 2,3-BDO, to fermentation products increased from $0.04 \mathrm{~g} / \mathrm{g}$ glucose under anaerobic conditions to
$1.65 \mathrm{~g} / \mathrm{g}$ glucose when $10 \%$ DO was used, which reflects the higher acetoin yields and also correlated to lower ethanol yields under aerobic conditions (Additional file 1: 

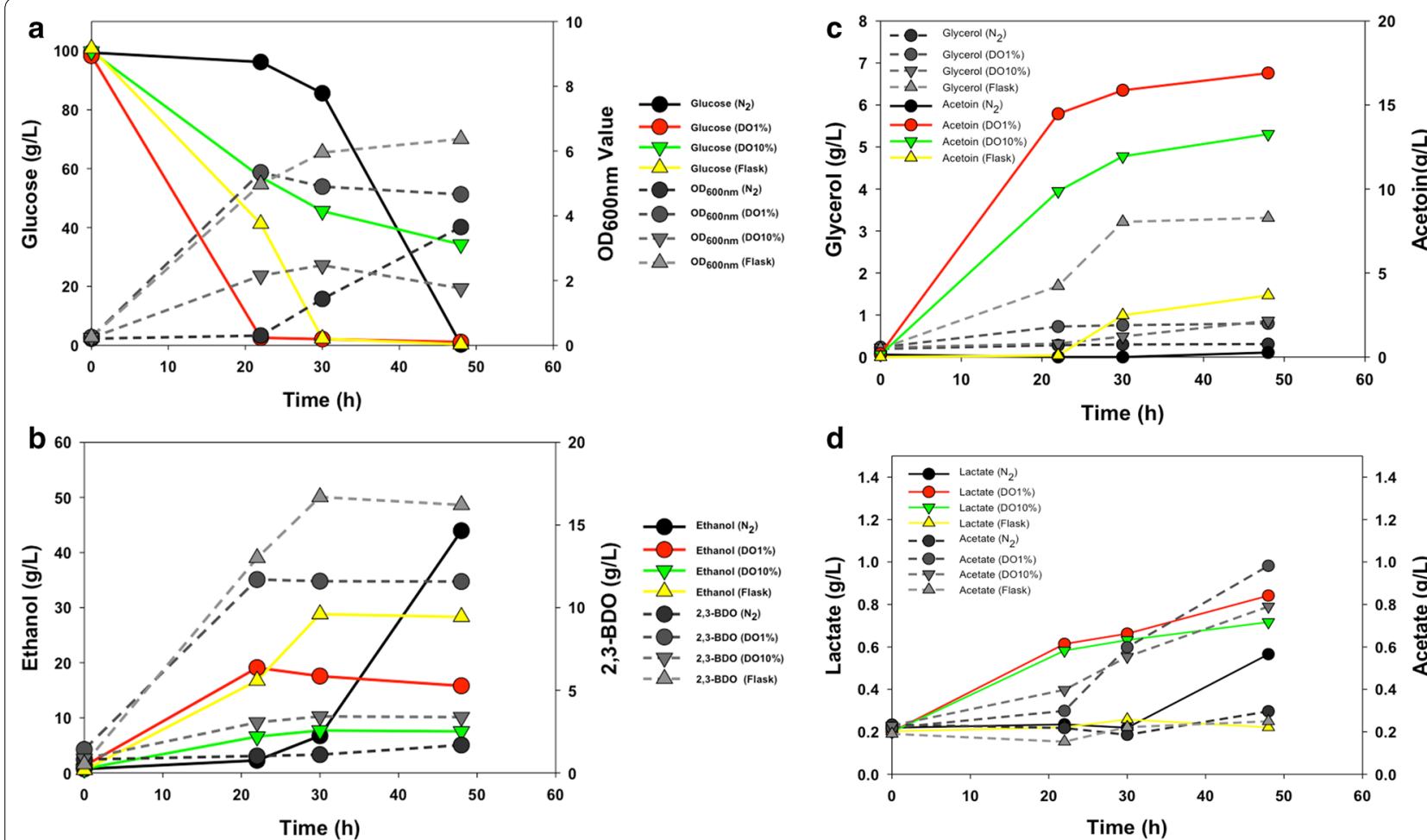

d

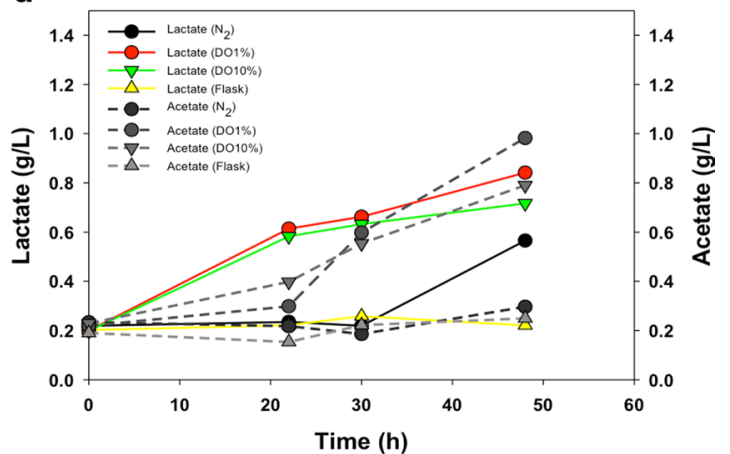

Fig. 5 BioStat-Q plus fermentation profiles of glucose utilization and biomass $\left(\mathrm{OD}_{600 \mathrm{~nm}}\right.$, a), 2,3-BDO and ethanol (b), acetoin and glycerol (c), acetate and lactate (d) of three-gene 2,3-BDO pathway construct Z. mobilis 9C-BC11 under different aeration conditions of $\mathrm{N}_{2}(0 \% \mathrm{DO}), 1$, or $10 \%$ $\mathrm{DO}$ (dissolved oxygen concentration) as well as shake flasks in RMG10 at pH 5.8 and $30^{\circ} \mathrm{C}$ conditions 48 -h post-inoculation

Table S1C). We saw a similar result with shake flask fermentations. Higher acetoin production was accompanied by lower ethanol titer under more aerobic conditions $(40 \mathrm{~mL}$ media in a $125-\mathrm{mL}$ flask at $120 \mathrm{rpm})$ (Fig. 3b).

\section{Discussion}

Zymomonas mobilis has attracted great attention due to its unique metabolic characteristics [49, 77-83]. Although it is missing two tricarboxylic acid cycle (TCA cycle) enzymes, malate dehydrogenase (Mdh) and 2-oxoglutarate dehydrogenase complex (Ogdh), as well as one key enzyme in the Embden-Meyerhof-Parnas (EMP) pathway (phosphofructokinase Pfk), Z. mobilis has outstanding fermentation performance consuming sugars at very high ethanol productivity rates and producing high ethanol titers through the Entner-Doudoroff (ED) pathway to provide energy for efficient growth. Glycolytic pathway enzymes are abundant in $Z$. mobilis which generate one ATP from each glucose molecule; compared to 2 ATPs generated from the EMP pathway and 38 ATPs from the TCA cycle. Zymomonas mobilis also has a respiration chain using oxygen as the terminal electron receptor under aerobic conditions. At least two branched electron transport systems have been proposed comprising NADH dehydrogenase (Ndh), coenzyme Q10, cytochrome bd, and $\mathrm{O}_{2}$, which has been confirmed by several studies [78, 81-87]. However, unlike other microorganisms, respiration in Z. mobilis is uncoupled to energetics and cellular growth with a function that has been suggested to maintain a low NADH/NAD ${ }^{+}$ratio for efficient glycolysis and cellular growth [87]. Disturbance of the cellular NADH/NAD ${ }^{+}$ratio due to external or internal inhibitors could lead to slow growth [48, 87]. A mutation of respiration chain genes, such as $n d h$ mutation, or the supplementation of respiration chain inhibitors could result in better growth and higher ethanol titer under aerobic conditions [78, 81, 82, 84, 87] possibly due to more NADH becoming available for ethanol fermentation. However, excessive NADH would result in a high NADH/NAD ${ }^{+}$ratio which would lead to inhibition of cellular growth [87]. Therefore, a well-balanced, low $\mathrm{NADH} / \mathrm{NAD}^{+}$ratio is key for efficient glycolysis and cellular growth in Z. mobilis.

Based on end-product data analysis for ethanol, acetoin, 2,3-BDO, lactate, acetate, and glycerol production, as well as cellular growth and glucose consumption profiles described above (Fig. 5), we propose the model below to explain the impact of host carbon and energetic 


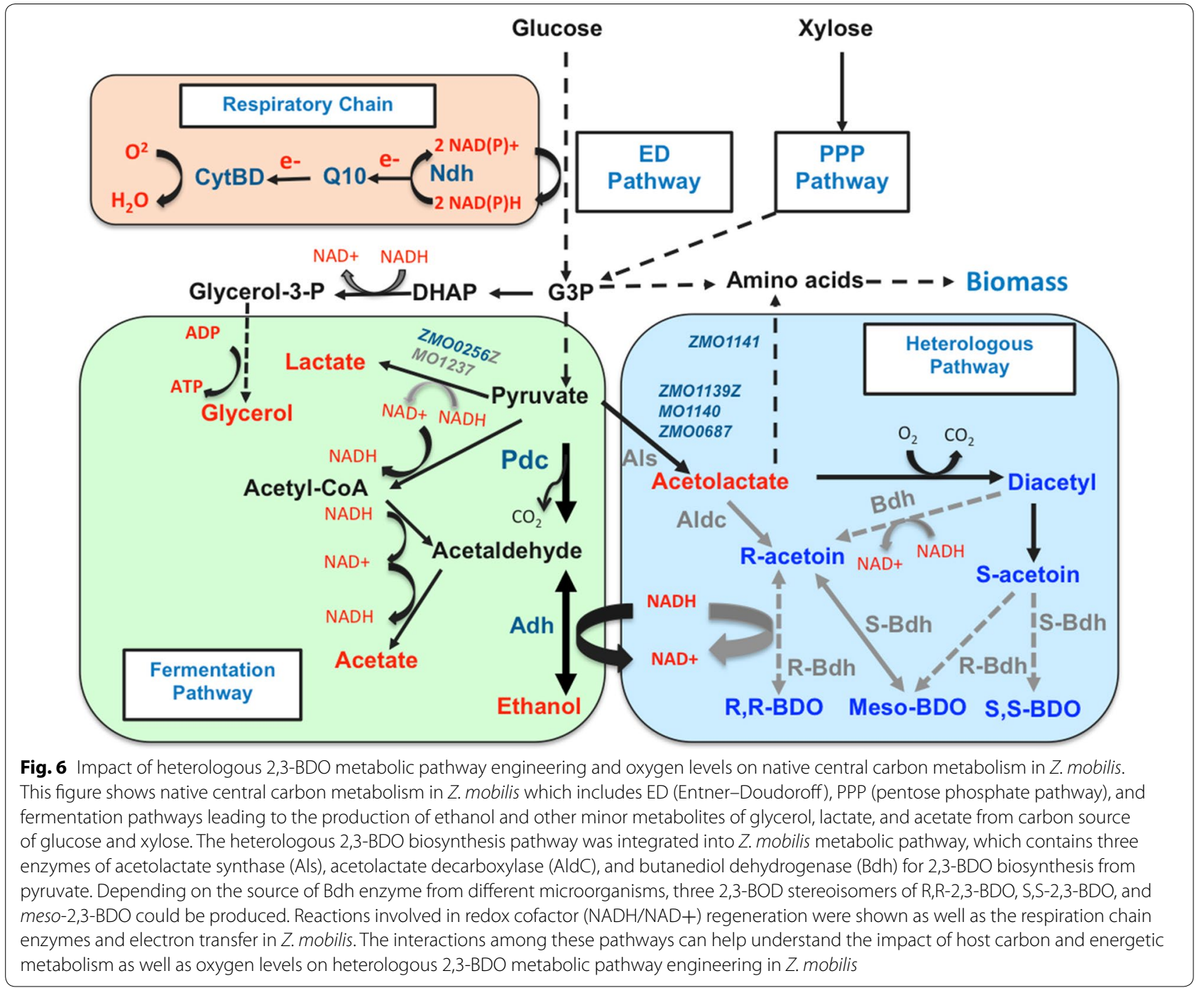

metabolism as well as oxygen levels on heterologous 2,3-BDO metabolic pathway engineering in Z. mobilis (Fig. 6).

We hypothesize that during anaerobic conditions, there is insufficient $\mathrm{NAD}^{+}$produced during ethanol fermentation to ensure efficient glucose catabolism in the engineered 2,3-BDO pathway in strain 9C-BC11 since pyruvate is being diverted away from ethanol production to 2,3-BDO. One acetolactate intermediate is synthesized from two pyruvate molecules by Als and then converted to acetoin and BDO by AldC and Bdh, respectively, oxidizing one $\mathrm{NADH}$ to generate one $\mathrm{NAD}^{+}$as opposed to two $\mathrm{NAD}^{+}$generated from ethanol fermentation. Moreover, the 2,3-BDO biosynthesis pathway may also compete for the substrate, acetolactate, with the branded-chain amino acids biosynthesis pathway for valine, alanine, and leucine. Taken together, the reduced $\mathrm{NAD}^{+}$generated via the heterologous 2,3-BDO metabolic pathway and the competition for substrate with the amino acid biosynthesis pathway may increase the $\mathrm{NADH} / \mathrm{NAD}^{+}$ratio, which could then reduce the glycolysis efficiency and cellular growth resulting in a long lag phase (Fig. 5a). This lag could last until sufficient $\mathrm{NAD}^{+}$could be generated to re-establish the optimal NADH/NAD ${ }^{+}$ratio for efficient ethanol production.

Under $1 \%$ DO culture conditions, we achieved the fastest glucose utilization and highest growth rates and the highest yields of 2,3-BDO and acetoin compared to anaerobic and $10 \%$ DO conditions, suggesting that a more optimal redox balance is achieved under this condition. However, lower 2,3-BDO titers were realized compared to shake flask conditions. Clearly, the highest oxygen level tested (10\%) negatively impacted glucose utilization, cellular growth, and end-product yields (Fig. $5 \mathrm{a}, \mathrm{b}, \mathrm{c}$ ), which may be due to an NADH/NAD ${ }^{+}$ ratio imbalance and thus inadequate $\mathrm{NADH}$ availability 
for 2,3-BDO biosynthesis and ethanol fermentation. Lactate dehydrogenase upregulated by oxygen may further exacerbate this situation by diverting needed NADH to lactate biosynthesis.

Under shake flask fermentation condition, more $\mathrm{NAD}^{+}$ may be generated from the acetoin to 2,3-BDO reaction, which could help maintain the redox balance. However, since the 2,3-BDO biosynthesis reaction is not as efficient as ethanol fermentation in Z. mobilis and NADH was not as efficiently recycled, we speculate that accumulation of more NADH is being diverted towards glycerol biosynthesis to regenerate $\mathrm{NAD}^{+}$while also providing ATP for glycolysis and cellular growth. Since shake flask conditions achieved higher 2,3-BDO and ethanol yields with lower acetoin production than either 1 or $10 \%$ DO fermentation conditions (Fig. 5b), we will further explore oxygenation levels and its impact on 2,3-BDO production and develop a strategy to balance redox to ensure maximum 2,3-BDO production under "anaerobic" or microaerophilic conditions.

The different physiological changes of a 2,3-BDO producer, therefore, could be contributed to the complex interplay between oxygen availability, the respiratory chain, oxygen and NADH cofactor requirement for heterologous 2,3-BDO biosynthesis and native glycolysis and ethanol fermentation pathways of $Z$. mobilis. In the presence of oxygen, $Z$. mobilis is able to oxidize NADH to $\mathrm{NAD}^{+}$by the NADH oxidase $\mathrm{Ndh}$ in the respiratory chain. High levels of acetoin formation under these conditions suggested that NADH is oxidized to $\mathrm{NAD}^{+}$by the NADH oxidase with high oxygen levels and will then not be available for the conversion of acetoin to 2,3-BDO by butanediol dehydrogenase (Bdh). Certainly, it is also possible that the activity of the $\mathrm{Bdh}$ is not optimal under these conditions and thus Bdh cannot compete with $\mathrm{NADH}$ oxidase. Further research will be needed to investigate the impact of oxygen, the fate of the NADH, and the Bdh enzymatic performance to optimize 2,3-BDO production and develop strategies for "anaerobic" production of 2,3-BDO in Z. mobilis.

\section{Conclusion}

In summary, we have demonstrated the successful redirection of carbon flux from ethanol production in $Z$. mobilis to production of other hydrocarbon intermediates, such as 2,3-BDO, from glucose and xylose or mixed sugars from pretreated biomass hydrolysate. Our results indicate that all three genes of the heterologous 2,3-BDO biosynthesis pathway are essential for high 2,3-BDO production in $Z$. mobilis, and the bottleneck reactions are both the acetolactate generation from pyruvate and the 2,3-BDO production from acetoin. Pathway engineering to introduce Als with strong enzyme activity on pyruvate for acetolactate generation increased 2,3-BDO titer. In addition, our results reveal the impact of host cellular metabolism and the effect of oxygen levels on heterologous 2,3-BDO metabolic pathway engineering for 2,3-BDO production in $Z$. mobilis which can illuminate potential strategies for anaerobic 2,3-BDO production improvement. Furthermore, our study confirms the value of integrating bioinformatics analysis and systems biology data during metabolic engineering endeavors.

\section{Methods}

\section{Bacterial strain and growth conditions}

Zymomonas mobilis 8b was revived from frozen glycerol stocks for about $6-8 \mathrm{~h}$ in $10 \mathrm{~mL}$ RMG2 $(20 \mathrm{~g} / \mathrm{L}$ glucose, $10 \mathrm{~g} / \mathrm{L}$ yeast extract, $\left.2 \mathrm{~g} / \mathrm{L} \mathrm{KH}_{2} \mathrm{PO}_{4}\right)$ at $33{ }^{\circ} \mathrm{C}$. Other $8 \mathrm{~b}$ derivatives used in this work are: $22 \mathrm{C}$, a hydrolysate-tolerant mutant strain; 9C, an $8 \mathrm{~b}$ derivative with both chloramphenicol and tetracycline resistance genes removed. The final spectinomycin concentration used for $\mathrm{Z}$. mobilis is 200 and $50 \mu \mathrm{g} / \mathrm{mL}$ for $E$. coli.

\section{Growth curve measurement using Bioscreen $\mathrm{C}$}

Growth of $Z$. mobilis was monitored by Bioscreen $\mathrm{C}$ using the 420-580 nm filter (Growth Curves USA, NJ) as described previously without shaking [88, 89]. Three replicates were used for each condition. The seed cultures used for Bioscreen $\mathrm{C}$ were first revived from frozen glycerol stocks overnight in RMG2, then diluted 100-fold into fresh RMG2 until it reached exponential phase. The absorbance at $\mathrm{OD}_{600 \mathrm{~nm}}$ was adjusted to 3 , then added $10-\mu \mathrm{L}$ to each well containing $290-\mu \mathrm{L}$ medium, such that the final $\mathrm{OD}_{600 \mathrm{~nm}}=0.1$. Procedures for measurement, recording of final cell densities, and calculations used to correct for non-linear response at high cell densities are previously reported $[88,89]$.

\section{Minimized shuttle vector construction and 2,3-BDO pathway assembly}

A new minimized shuttle vector, pEZ15Asp, was designed and synthesized that includes origins of replication from both E. coli and Z. mobilis, antibiotics marker for the spectinomycin resistance gene, and multiple cloning sites for Biobrick-based pathway assembly [67].

Wild-type and codon-optimized versions of three 2,3-BDO biosynthesis pathway genes were synthesized by Genscript (NJ, USA). The genes were then assembled in different combinations using Biobrick-based approaches. Specifically, the minimized shuttle vector pEZ15Asp (pEZ) was digested with EcoRI-HF and PstIHF (Bio-Rad, CA), which was treated using the Rapid DNA Dephos and Ligation Kit (Roche, CA) for dephosphorylation and then quantified using Nanodrop and gel electrophoresis followed by gel purification. The insert(s) 
were also treated with restriction enzymes of EcoRI/SpeI or XbaI/Pst and then quantified again using Nanodrop and gel electrophoresis followed by gel purification. The insert and vector were ligated using the fast-ligation kit (NEB, CA) with a molecular ratio of 3:1 for insert to vector. The ligation product $(2-\mu \mathrm{L})$ was used for transformation into NEB C2925 competent cells. The transformants were confirmed by colony PCR using the primers of pBAD-GFP_F/R (5'TCACCAGCTCACCGTCTTTC ${ }^{\prime}$ and $5^{\prime}$ CCTGATGAATGCTCATCCGG3') to confirm the insert size. The gene-specific primers were used to confirm that the targeted genes were cloned into the vector. Colonies showing the expected PCR bands were inoculated into LB broth supplemented with $50 \mu \mathrm{g} / \mathrm{mL}$ spectinomycin overnight and the plasmids were extracted and confirmed by PCR, restriction digestion, and Sanger sequencing.

\section{Electroporation transformation and 2,3-BDO strain selection}

Zymomonas mobilis or Escherichia coli cells were transformed with plasmids by electroporation (Bio-Rad Gene Pulser, 0.1-cm gap cuvettes, $1.6 \mathrm{kV}, 200 \mathrm{ohms}, 25 \mu \mathrm{F}$ ). Electrocompetent $Z$. mobilis cells were prepared by centrifuging cells from cultures that had reached an $\mathrm{OD}_{600 \mathrm{~nm}}$ of 0.4-0.6. Cell pellets were washed once in ice-cold sterile water, re-centrifuged, and washed again in $10 \%$ glycerol. These pellets were resuspended in $10 \%$ glycerol at a concentration approximately 1000 -fold higher than the starting culture. Competent cells were stored at $-80{ }^{\circ} \mathrm{C}$ as small aliquots for later use. Transformants of $E$. coli or Z. mobilis were selected on LB or RMG agar plates, respectively, containing appropriate antibiotics. Due to the presence of restriction/modification systems in $Z$. mobilis [90] that can decrease transformation efficiency, all plasmids were built in and isolated from a methylation-deficient E. coli strain, C2925 (NEB, MA), for efficient transformation into $Z$. mobilis $8 \mathrm{~b}$ or its derivatives.

For single colony isolation, transformants grown on the selective plates containing spectinomycin were further streaked on RMG plates with spectinomycin at a final concentration of $200 \mu \mathrm{g} / \mathrm{mL}$ (RMGSp). Following isolation, these colonies were then used for colony PCR to confirm the introduction of plasmids with correct pathway genes using the primers pBAD-GFP_F/R to check the insert size and gene-specific primers. Colonies with expected PCR bands pattern were selected and inoculated into RMGSp for preservation and further flask evaluation.

\section{Lignocellulosic biomass sugar hydrolysate}

Biomass sugar hydrolysates were prepared using DMR corn stover. The details of DMR pretreatment process were described elsewhere [42]. In brief, corn stover (INL LOT\#6, harvested in Hurley County, SD) was knife milled to pass through a $19 \mathrm{~mm}(3 / 4$-in.) rejection screen followed by dilute alkaline $(\mathrm{NaOH}$ at $0.1 \mathrm{M})$ deacetylation at $80{ }^{\circ} \mathrm{C}$ in a $1900-\mathrm{L}$ paddle mixer to remove most of the acetyl groups and some of the lignin. The deacetylated corn stover was disc refined at a specific refining energy of approximately $100 \mathrm{~kW} / \mathrm{ODMT}$ in a pilot scale Sprout 401 (36-in.) disc refiner provided by Andritz, Inc., Springfield, OH. A secondary milling was applied to the deacetylated and disc refined corn stover substrates at $100 \mathrm{kWh} / O D M T$ using a planetary type Szego mill to further improve digestibility. The DMR-pretreated corn stover was then hydrolyzed using cellulases from Novozyme as reported previously [41]. The hydrolysis was conducted at $15 \%$ total solids, $\mathrm{pH} 5.2,50{ }^{\circ} \mathrm{C}$ and completed in 5 days.

\section{Shake flasks and Biostat- $Q$ fermentations}

Seed cultures of $Z$. mobilis strains harvested at exponential phase were inoculated into $125-\mathrm{mL}$ shake flasks containing 40-mL media of RMG8 (RM with $80 \mathrm{~g} / \mathrm{L}$ glucose) or RMG8X6 (RM with $80 \mathrm{~g} / \mathrm{L}$ glucose and $60 \mathrm{~g} / \mathrm{L}$ xylose) to a starting $\mathrm{OD}_{600 \mathrm{~nm}}$ of 0.1 . The medium was supplemented with spectinomycin at a final concentration of $200 \mu \mathrm{g} / \mathrm{mL}$. The temperature was maintained at 30 or $33^{\circ} \mathrm{C}$ with a shaking speed of $120 \mathrm{rpm}$.

For BiosStat-Q Plus fermentations, strains were revived from frozen stock on RMG5 (50 g/L glucose) in $50 \mathrm{~mL}$ baffled flasks containing $10 \mathrm{~mL}$ of media, and incubated overnight at $30{ }^{\circ} \mathrm{C}$ in a shaking incubator at $180 \mathrm{rpm}$. The revived and grown culture was used to start the seed culture for fermentation. The seed cultures were then prepared in $125 \mathrm{~mL}$ shake flasks containing $40 \mathrm{~mL}$ RMG8 (80 g/L glucose) using revived cultures and inoculated at an initial $\mathrm{OD}_{600 \mathrm{~nm}}$ of 0.1 . Seed flasks were incubated at $30{ }^{\circ} \mathrm{C}$ overnight in a shaking incubator at $180 \mathrm{rpm}$. Fermentations to evaluate the strains for $\mathrm{BDO}$ production were carried out in BioStat- $Q$ plus fermenters with a 300$\mathrm{mL}$ working volume of RMG with higher glucose concentration of $100 \mathrm{~g} / \mathrm{L}$ (RMG10) to investigate whether higher carbon source could increase 2,3-BDO titer. The media were supplemented with spectinomycin at the final concentration of $200 \mu \mathrm{g} / \mathrm{mL}$. The fermenters were inoculated from an overnight grown seed culture with an initial $\mathrm{OD}_{600 \mathrm{~nm}}$ value of 0.1 . The fermenter operated at $30{ }^{\circ} \mathrm{C}$, $300 \mathrm{rpm}$, and controlled at pH 5.8 with $4 \mathrm{~N} \mathrm{KOH}$.

\section{High-performance liquid chromatography (HPLC)}

The dry weight of cells at the end of fermentation was determined by centrifuging $10 \mathrm{~mL}$ of broth and washing the cells with double deionized $\mathrm{H}_{2} \mathrm{O}$. The washed cells were placed in pre-weighed aluminum dishes and dried 
overnight at an $85^{\circ} \mathrm{C}$ incubator. The correlation between dry cell weight and $\mathrm{OD}_{600 \mathrm{~nm}}$ value was then calculated and used to estimate the dry cell weight in other time points.

Samples from the shake flasks or fermenters were taken at various time points. The samples were diluted for $\mathrm{OD}_{600 \mathrm{~nm}}$ measurement. In addition, samples were filtered through a $0.2-\mu \mathrm{m}$ syringe filter into HPLC vials. Concentrations of glucose, xylose, 2,3-BDO, acetoin, xylitol, ethanol, HMF, furfural, lactic acid, glycerol, and acetic acid were determined from filtered sample supernatants by Agilent 1100 series HPLC (Agilent, CA) utilizing a BioRad Aminex HPX-87H organic acids column and Cation $\mathrm{H}^{+}$guard cartridge (Bio-Rad, CA) operating at $65{ }^{\circ} \mathrm{C}$. A refractive index detector was used for compound detection. Dilute sulfuric acid $(0.01 \mathrm{~N})$ was used as the isocratic mobile phase at a flow rate of $0.6 \mathrm{~mL} /$ min, following published procedures [41]. Sugar utilization, 2,3-BDO, acetoin, and ethanol titers were calculated based on the HPLC and dry cell weight data.

\section{Additional file}

Additional file 1:Table S1. Sequence information for constructs and major plasmids (1 A) used in this work, systems biology datasets used to evaluate $Z$. mobilis genes that may potentially affect lactate and heterologous 2,3-BDO production (1B), as well as fermentation data and yield at different conditions (1C).

\begin{abstract}
Abbreviations
2,3-BDO: 2,3-butanediol; Als: acetolactate synthase; AldC: acetolactate decarboxylase; Bdh: butanediol dehydrogenase; Pdc: pyruvate decarboxylase; Adh: alcohol dehydrogenase; Mdh: malate dehydrogenase; Ogdh: 2-oxoglutarate dehydrogenase complex; Ndh: NADH dehydrogenase; TCA cycle: tricarboxylic acid cycle; EMP: Embden-Meyerhof-Parnas pathway; ED: Entner-Doudoroff pathway; DDR: deacetylation and disc-refining; DMR: deacetylation and mechanical refining; NGS: next-generation sequencing; HPLC: high-performance liquid chromatography.
\end{abstract}

\section{Authors' contributions}

SY carried out minimized vector construction, pathway construction, metabolic engineering, flask fermentation experiment and HPLC, and wrote the manuscript. AM and ND carried out the Biostat- $\mathrm{Q}$ fermentation experiment and corresponding HPLC. MAF carried out the bio-toxicity Bioscreen C experiment for meso-2,3-BDO and ethanol. YCC constructed the $9 \mathrm{C}$ strain and helped with pathway construction. XC performed DMR pretreatment and generated the DMR hydrolysate material. MZ and MEH supervised the project. All authors participated in experiment design, data interpretation, and manuscript revision. All authors read and approved the final manuscript.

\section{Author details \\ ${ }^{1}$ National Bioenergy Center, National Renewable Energy Laboratory, Golden 80401, USA. ${ }^{2}$ Biosciences Center, National Renewable Energy Laboratory, Golden, CO 80401, USA. ${ }^{3}$ Present Address: Hubei Collaborative Innovation Center for Green Transformation of Bio-resources, Hubei Key Labo- ratory of Industrial Biotechnology, College of Life Sciences, Hubei University, Wuhan 430062, China.}

\section{Acknowledgements}

We would like to acknowledge our colleagues Qiang Fei for help on BioStat- $Q$ plus fermentation and Deborah Hyman for the establishment of HPLC method to quantify $2,3-\mathrm{BDO}$ fermentation products.

\section{Competing interests}

The authors declare that they have no competing interests.

\section{Funding}

The funding support was from the BioEnergy Technologies Office (BETO) program in the U.S. DOE Office of Energy Efficiency and Renewable Energy (EERE) under the contract \# DE-AC36-08GO28308.

Received: 7 April 2016 Accepted: 26 August 2016

Published online: 02 September 2016

\section{References}

1. Celinska E, Grajek W. Biotechnological production of 2,3-butanediol-current state and prospects. Biotechnol Adv. 2009;27(6):715-25.

2. Syu MJ. Biological production of 2,3-butanediol. Appl Microbiol Biotechnol. 2001;55(1):10-8.

3. Ji XJ, Huang H, Ouyang PK. Microbial 2,3-butanediol production: a stateof-the-art review. Biotechnol Adv. 2011;29(3):351-64.

4. Zeng A-P, Sabra W. Microbial production of diols as platform chemicals: recent progresses. Curr Opin Biotechnol. 2011;22(6):749-57.

5. Kim S, Hahn JS. Efficient production of 2,3-butanediol in Saccharomyces cerevisiae by eliminating ethanol and glycerol production and redox rebalancing. Metab Eng. 2015;31:94-101.

6. Kim JW, Seo SO, Zhang GC, Jin YS, Seo JH. Expression of Lactococcus lactis NADH oxidase increases 2,3-butanediol production in Pdc-deficient Saccharomyces cerevisiae. Bioresour Technol. 2015;191:512-9.

7. $\mathrm{Nan} \mathrm{H}$, Seo SO, Oh EJ, Seo JH, Cate JH, Jin YS. 2,3-butanediol production from cellobiose by engineered Saccharomyces cerevisiae. Appl Microbiol Biotechnol. 2014;98(12):5757-64.

8. Lian J, Chao R, Zhao H. Metabolic engineering of a Saccharomyces cerevisiae strain capable of simultaneously utilizing glucose and galactose to produce enantiopure (2R,3R)-butanediol. Metab Eng. 2014;23:92-9.

9. Kim SJ, Seo SO, Park YC, Jin YS, Seo JH. Production of 2,3-butanediol from xylose by engineered Saccharomyces cerevisiae. J Biotechnol. 2014;192(Pt B):376-82.

10. Kim SJ, Seo SO, Jin YS, Seo JH. Production of 2,3-butanediol by engineered Saccharomyces cerevisiae. Bioresour Technol. 2013;146:274-81.

11. Ng CY, Jung MY, Lee J, Oh MK. Production of 2,3-butanediol in Saccharomyces cerevisiae by in silico aided metabolic engineering. Microb Cell Fact. 2012;11:68.

12. Ma C, Wang A, Qin J, Li L, Ai X, Jiang T, Tang H, Xu P. Enhanced 2,3-butanediol production by Klebsiella pneumoniae SDM. Appl Microbiol Biotechnol. 2009;82(1):49-57.

13. Xu Y, Wang A, Tao F, Su F, Tang H, Ma C, Xu P. Genome sequence of Enterobacter cloacae subsp. dissolvens SDM, an efficient biomass-utilizing producer of platform chemical 2,3-butanediol. J Bacteriol. 2012:194(4):897-8.

14. Li L, Wang Y, Li K, Su F, Ma C, Xu P. Genome sequence of meso-2,3-butanediol-producing strain Serratia marcescens ATCC 14041. Genome Announc. 2014;2(3):e00590.

15. Li L, Zhang L, Li K, Wang Y, Gao C, Han B, Ma C, Xu P. A newly isolated Bacillus licheniformis strain thermophilically produces 2,3-butanediol, a platform and fuel bio-chemical. Biotechnol Biofuels. 2013;6(1):123.

16. Xu Y, Chu H, Gao C, Tao F, Zhou Z, Li K, Li L, Ma C, Xu P. Systematic metabolic engineering of Escherichia coli for high-yield production of fuel bio-chemical 2,3-butanediol. Metab Eng. 2014;23:22-33.

17. Kay JE, Jewett MC. Lysate of engineered Escherichia coli supports high-level conversion of glucose to 2,3-butanediol. Metab Eng. 2015;32:133-42.

18. Shin HD, Yoon SH, Wu J, Rutter C, Kim SW, Chen RR. High-yield production of meso-2,3-butanediol from cellodextrin by engineered E. coli biocatalysts. Bioresour Technol. 2012;118:367-73.

19. Lee S, Kim B, Park K, Um Y, Lee J. Synthesis of pure meso-2,3-butanediol from crude glycerol using an engineered metabolic pathway in Escherichia coli. Appl Biochem Biotechnol. 2012;166(7):1801-13.

20. Li ZJ, Jian J, Wei XX, Shen XW, Chen GQ. Microbial production of meso2,3-butanediol by metabolically engineered Escherichia coli under low oxygen condition. Appl Microbiol Biotechnol. 2010;87(6):2001-9. 
21. Nielsen DR, Yoon SH, Yuan CJ, Prather KL. Metabolic engineering of acetoin and meso-2, 3-butanediol biosynthesis in E. coli. Biotechnol J. 2010;5(3):274-84

22. Nozzi NE, Atsumi S. Genome engineering of the 2,3-butanediol biosynthetic pathway for tight regulation in Cyanobacteria. ACS Synth Biol. 2015;4(11):1197-204.

23. Oliver JW, Machado IM, Yoneda H, Atsumi S. Combinatorial optimization of cyanobacterial 2,3-butanediol production. Metab Eng. 2014;22:76-82.

24. Li L, Wang Y, Zhang L, Ma C, Wang A, Tao F, Xu P. Biocatalytic production of (2S,3S)-2,3-butanediol from diacetyl using whole cells of engineered Escherichia coli. Bioresour Technol. 2012:115:111-6.

25. Tong YJ, Ji XJ, Shen MQ, Liu LG, Nie ZK, Huang H. Constructing a synthetic constitutive metabolic pathway in Escherichia coli for ( $R, R)-2,3$-butanediol production. Appl Microbiol Biotechnol. 2016;100(2):637-47.

26. Ji XJ, Liu LG, Shen MQ, Nie ZK, Tong YJ, Huang H. Constructing a synthetic metabolic pathway in Escherichia coli to produce the enantiomerically pure (R, R)-2,3-butanediol. Biotechnol Bioeng. 2015;112(5):1056-9.

27. Ui S, Takusagawa Y, Sato T, Ohtsuki T, Mimura A, Ohkuma M, Kudo T. Production of L-2,3-butanediol by a new pathway constructed in Escherichia coli. Lett Appl Microbiol. 2004;39(6):533-7.

28. Ui S, Takusagawa Y, Ohtsuki T, Mimura A, Ohkuma M, Kudo T. Stereochemical applications of the expression of the L-2,3-butanediol dehydrogenase gene in Escherichia coli. Lett Appl Microbiol. 2001;32(2):93-8.

29. Zhang L, Guo Z, Chen J, Xu Q, Lin H, Hu K, Guan X, Shen Y. Mechanism of 2,3-butanediol stereoisomers formation in a newly isolated Serratia sp T241. Sci Rep. 2016;6:19257.

30. Qi G, Kang Y, Li L, Xiao A, Zhang S, Wen Z, Xu D, Chen S. Deletion of meso2,3-butanediol dehydrogenase gene budC for enhanced D-2,3-butanedio production in Bacillus licheniformis. Biotechnol Biofuels. 2014;7(1):16.

31. Qiu Y, Zhang J, Li L, Wen Z, Nomura CT, Wu S, Chen S. Engineering Bacillus licheniformis for the production of meso-2,3-butanediol. Biotechnol Biofuels. 2016;9:117

32. Liu Z, Qin J, Gao C, Hua D, Ma C, Li L, Wang Y, Xu P. Production of (2S,3S)-2,3-butanediol and (3S)-acetoin from glucose using resting cells of Klebsiella pneumonia and Bacillus subtilis. Bioresour Technol. 2011;102(22):10741-4.

33. Li L, Li K, Wang Y, Chen C, Xu Y, Zhang L, Han B, Gao C, Tao F, Ma C, et al. Metabolic engineering of Enterobacter cloacae for high-yield production of enantiopure (2R,3R)-2,3-butanediol from lignocellulose-derived sugars. Metab Eng. 2015:28:19-27.

34. Mohagheghi A, Evans K, Chou YC, Zhang M. Cofermentation of glucose, xylose, and arabinose by genomic DNA-integrated xylose/arabinose fermenting strain of Zymomonas mobilis AX101. Appl Biochem Biotechnol. 2002:98-100:885-98.

35. Mohagheghi A, Evans K, Finkelstein M, Zhang M. Cofermentation of glucose, xylose, and arabinose by mixed cultures of two genetically engineered Zymomonas mobilis strains. Appl Biochem Biotechnol. 1998;70-72:285-99.

36. Mohagheghi A, Linger J, Smith H, Yang S, Dowe N, Pienkos PT. Improving xylose utilization by recombinant Zymomonas mobilis strain $8 \mathrm{~b}$ through adaptation using 2-deoxyglucose. Biotechnol Biofuels. 2014;7(1):19.

37. Zhang M, Eddy C, Deanda K, Finkelstein M, Picataggio S. Metabolic engineering of a pentose metabolism pathway in ehanologenic Zymomonas mobilis. Science. 1995;267(5195):240-3.

38. He MX, Wu B, Qin H, Ruan ZY, Tan FR, Wang JL, Shui ZX, Dai LC, Zhu QL, Pan K, et al. Zymomonas mobilis: a novel platform for future biorefineries. Biotechnol Biofuels. 2014;7:101.

39. Chen X, Shekiro J, Franden MA, Wang W, Zhang M, Kuhn E, Johnson DK, Tucker MP. The impacts of deacetylation prior to dilute acid pretreatment on the bioethanol process. Biotechnol Biofuels. 2012;5:8.

40. Chen X, Tao L, Shekiro J, Mohaghaghi A, Decker S, Wang W, Smith H, Park S, Himmel ME, Tucker M. Improved ethanol yield and reduced minimum ethanol selling price (MESP) by modifying low severity dilute acid pretreatment with deacetylation and mechanical refining: 1) experimental. Biotechnol Biofuels. 2012;5(1):60.

41. Chen X, Kuhn E, Jennings EW, Nelson R, Tao L, Zhang M, Tucker MP. DMR (deacetylation and mechanical refining) processing of corn stover achieves high monomeric sugar concentrations (230 g L-1) during enzymatic hydrolysis and high ethanol concentrations (>10\% v/v) during fermentation without hydrolysate purification or concentration. Energy Environ Sci. 2016:9(4):1237-45.
42. Chen X, Wang W, Ciesielski PN, Trass O, Park S, Tao L, Tucker M. Improving sugar yields and reducing enzyme loadings in the deacetylation and mechanical Refining (DMR) process through multi-stage disk and Szego refining and corresponding techno economic analysis. ACS Sustain Chem Eng. 2015;4(1):324-33.

43. Mohagheghi A, Linger JG, Yang S, Smith H, Dowe N, Zhang M, Pienkos PT. Improving a recombinant Zymomonas mobilis strain 8b through continuous adaptation on dilute acid pretreated corn stover hydrolysate. Biotechnol Biofuels. 2015;8:55.

44. Yang S, Linger J, Franden MA, Pienkos PT, Zhang M. Biocatalysts with enhanced inhibitor tolerance. In: USPTO. Biocatalysts with enhanced inhibitor tolerance. US9206445. 2015.

45. Shui ZX, Qin H, Wu B, Ruan ZY, Wang LS, Tan FR, Wang JL, Tang XY, Dai LC, $\mathrm{Hu} \mathrm{GQ}$, et al. Adaptive laboratory evolution of ethanologenic Zymomonas mobilis strain tolerant to furfural and acetic acid inhibitors. Appl Microbiol Biotechnol. 2015:99(13):5739-48.

46. Tan FR, Dai LC, Wu B, Qin H, Shui ZX, Wang JL, Zhu QL, Hu QC, Ruan $Z Y$, He MX. Improving furfural tolerance of Zymomonas mobilis by rewiring a sigma factor RpoD protein. Appl Microbiol Biotechnol. 2015:99(12):5363-71.

47. Tan F, Wu B, Dai L, Qin H, Shui Z, Wang J, Zhu Q, Hu G, He M. Using global transcription machinery engineering (gTME) to improve ethanol tolerance of Zymomonas mobilis. Microb Cell Fact. 2016;15:4.

48. Wang JL, Wu B, Qin H, You Y, Liu S, Shui ZX, Tan FR, Wang YW, Zhu QL, $\mathrm{Li} Y \mathrm{~B}$, et al. Engineered Zymomonas mobilis for salt tolerance using EZ-Tn5-based transposon insertion mutagenesis system. Microb Cell Fact. 2016;15(1):101.

49. Dong HW, Fan LQ, Luo Z, Zhong JJ, Ryu DD, Bao J. Improvement of ethanol productivity and energy efficiency by degradation of inhibitors using recombinant Zymomonas mobilis (pHW20a-fdh). Biotechnol Bioeng. 2013;110(9):2395-404.

50. Yang S, Pappas KM, Hauser LJ, Land ML, Chen GL, Hurst GB, Pan C, Kouvelis VN, Typas MA, Pelletier DA, et al. Improved genome annotation for Zymomonas mobilis. Nat Biotechnol. 2009;27(10):893-4.

51. Seo JS, Chong H, Park HS, Yoon KO, Jung C, Kim JJ, Hong JH, Kim H, Kim $J \mathrm{H}, \mathrm{Kil} \mathrm{Jl}$, et al. The genome sequence of the ethanologenic bacterium Zymomonas mobilis ZM4. Nat Biotechnol. 2005;23(1):63-8.

52. Zhang K, Shao H, Cao Q, He MX, Wu B, Feng H. Transcriptional analysis of adaptation to high glucose concentrations in Zymomonas mobilis. Appl Microbiol Biotechnol. 2015;99(4):2009-22.

53. Yi X, Gu H, Gao Q, Liu ZL, Bao J. Transcriptome analysis of Zymomonas mobilis ZM4 reveals mechanisms of tolerance and detoxification of phenolic aldehyde inhibitors from lignocellulose pretreatment. Biotechnol Biofuels. 2015:8:153.

54. Yang S, Pan C, Hurst GB, Dice L, Davison BH, Brown SD. Elucidation of Zymomonas mobilis physiology and stress responses by quantitative proteomics and transcriptomics. Front Microbiol. 2014;5:246.

55. Yang S, Franden MA, Brown SD, Chou YC, Pienkos PT, Zhang M. Insights into acetate toxicity in Zymomonas mobilis 8b using different substrates. Biotechnol Biofuels. 2014;7(1):140.

56. Kalnenieks U, Pentjuss A, Rutkis R, Stalidzans E, Fell DA. Modeling of Zymomonas mobilis central metabolism for novel metabolic engineering strategies. Front Microbiol. 2014;5:42.

57. Yang S, Pan C, Tschaplinski TJ, Hurst GB, Engle NL, Zhou W, Dam P, Xu $Y$, Rodriguez M Jr, Dice L, et al. Systems biology analysis of Zymomonas mobilis ZM4 ethanol stress responses. PLoS One. 2013;8(7):e68886.

58. He MX, Wu B, Shui ZX, Hu QC, Wang WG, Tan FR, Tang XY, Zhu QL, Pan K, $\mathrm{Li} Q$, et al. Transcriptome profiling of Zymomonas mobilis under furfural stress. Appl Microbiol Biotechnol. 2012;95(1):189-99.

59. He MX, Wu B, Shui ZX, Hu QC, Wang WG, Tan FR, Tang XY, Zhu QL, Pan K, $\mathrm{Li}$ Q, et al. Transcriptome profiling of Zymomonas mobilis under ethanol stress. Biotechnol Biofuels. 2012;5(1):75.

60. Widiastuti H, Kim JY, Selvarasu S, Karimi IA, Kim H, Seo JS, Lee DY. Genome-scale modeling and in silico analysis of ethanologenic bacteria Zymomonas mobilis. Biotechnol Bioeng. 2011;108(3):655-65.

61. Yang S, Land ML, Klingeman DM, Pelletier DA, Lu TY, Martin SL, Guo HB, Smith JC, Brown SD. Paradigm for industrial strain improvement identifies sodium acetate tolerance loci in Zymomonas mobilis and Saccharomyces cerevisiae. Proc Natl Acad Sci USA. 2010;107(23):10395-400. 
62. Bochner B, Gomez V, Ziman M, Yang S, Brown SD. Phenotype microarray profiling of Zymomonas mobilis ZM4. Appl Biochem Biotechnol. 2010;161(1-8):116-23.

63. Yang S, Tschaplinski TJ, Engle NL, Carroll SL, Martin SL, Davison BH, Palumbo AV, Rodriguez M Jr, Brown SD. Transcriptomic and metabolomic profiling of Zymomonas mobilis during aerobic and anaerobic fermentations. BMC Genom. 2009;10:34.

64. Skerker JM, Leon D, Price MN, Mar JS, Tarjan DR, Wetmore KM, Deutschbauer AM, Baumohl JK, Bauer S, Ibanez AB, et al. Dissecting a complex chemical stress: chemogenomic profiling of plant hydrolysates. Mol Syst Biol. 2013;9:674.

65. Cho SH, Lei R, Henninger TD, Contreras LM. Discovery of ethanolresponsive small RNAs in Zymomonas mobilis. Appl Environ Microbiol. 2014;80(14):4189-98.

66. Gu H, Zhang J, Bao J. High tolerance and physiological mechanism of Zymomonas mobilis to phenolic inhibitors in ethanol fermentation of corncob residue. Biotechnol Bioeng. 2015;112(9):1770-82.

67. Shetty RP, Endy D, Knight TF Jr. Engineering BioBrick vectors from BioBrick parts. J Biol Eng. 2008;2:5.

68. de Oliveira RR, Nicholson WL. Synthetic operon for (R, R)-2,3-butanediol production in Bacillus subtilis and Escherichia coli. Appl Microbiol Biotechnol. 2016;100(2):719-28.

69. Blomqvist K, Nikkola M, Lehtovaara P, Suihko ML, Airaksinen U, Straby KB, Knowles JK, Penttila ME. Characterization of the genes of the 2,3-butanediol operons from Klebsiella terrigena and Enterobacter aerogenes. J Bacteriol. 1993;175(5):1392-404.

70. Xu GC, Bian YQ, Han RZ, Dong JJ, Ni Y. Cloning, expression, and characterization of budC gene encoding meso-2,3-butanediol dehydrogenase from Bacillus licheniformis. Appl Biochem Biotechnol. 2016;178(3):604-17.

71. Saha BC, Bothast RJ. Production of 2,3-butanediol by newly isolated Enterobacter cloacae. Appl Microbiol Biotechnol. 1999;52(3):321-6.

72. Bae SJ, Kim S, Hahn JS. Efficient production of acetoin in Saccharomyces cerevisiae by disruption of 2,3-butanediol dehydrogenase and expression of NADH oxidase. Sci Rep. 2016;6:27667.

73. Kim S, Hahn JS. Synthetic scaffold based on a cohesin-dockerin interaction for improved production of 2,3-butanediol in Saccharomyces cerevisiae. J Biotechnol. 2014;192(Pt A):192-6.

74. Kim S, Bae S-J, Hahn J-S. Redirection of pyruvate flux toward desired metabolic pathways through substrate channeling between pyruvate kinase and pyruvate-converting enzymes in Saccharomyces cerevisiae. Sci Rep. 2016;6:24145.

75. Welch P, Scopes RK. Studies on cell-free metabolism: ethanol production by a yeast glycolytic system reconstituted from purified enzymes. J Biotechnol. 1985;2(5):257-73.

76. Snoep JL, Yomano LP, Westerhoff HV, Ingram LO. Protein burden in Zymomonas mobilis: negative flux and growth control due to overproduction of glycolytic enzymes. Microbiology. 1995;141(9):2329-37.
77. Kalnenieks U, Galinina N, Toma MM, Pickford JL, Rutkis R, Poole RK. Respiratory behaviour of a Zymomonas mobilis adhB:kan(r) mutant supports the hypothesis of two alcohol dehydrogenase isoenzymes catalysing opposite reactions. FEBS Lett. 2006;580(21):5084-8.

78. Sootsuwan K, Lertwattanasakul N, Thanonkeo P, Matsushita K, Yamada M. Analysis of the respiratory chain in Ethanologenic Zymomonas mobilis with a cyanide-resistant bd-type ubiquinol oxidase as the only terminal oxidase and its possible physiological roles. J Mol Microbiol Biotechnol. 2008;14(4):163-75.

79. Jeon BY, Hwang TS, Park DH. Electrochemical and biochemical analysis of ethanol fermentation of zymomonas mobilis KCCM11336. J Microbiol Biotechnol. 2009;19(7):666-74.

80. Hayashi T, Furuta Y, Furukawa K. Respiration-deficient mutants of Zymomonas mobilis show improved growth and ethanol fermentation under aerobic and high temperature conditions. J Biosci Bioeng. 2011;111(4):414-9.

81. Hayashi T, Kato T, Furukawa K. Respiratory chain analysis of Zymomonas mobilis mutants producing high levels of ethanol. Appl Environ Microbiol. 2012;78(16):5622-9.

82. Strazdina I, Kravale Z, Galinina N, Rutkis R, Poole RK, Kalnenieks U. Electron transport and oxidative stress in Zymomonas mobilis respiratory mutants. Arch Microbiol. 2012;194(6):461-71.

83. Balodite E, Strazdina I, Galinina N, McLean S, Rutkis R, Poole RK, Kalnenieks U. Structure of the Zymomonas mobilis respiratory chain: oxygen affinity of electron transport and the role of cytochrome c peroxidase. Microbiology. 2014;160(Pt 9):2045-52.

84. Kalnenieks U, Galinina N, Strazdina I, Kravale Z, Pickford JL, Rutkis R, Poole RK. NADH dehydrogenase deficiency results in low respiration rate and improved aerobic growth of Zymomonas mobilis. Microbiology. 2008;154(Pt 3):989-94.

85. Kim YJ, Song KB, Rhee SK. A novel aerobic respiratory chain-linked NADH oxidase system in Zymomonas mobilis. J Bacteriol. 1995;177(17):5176-8.

86. Charoensuk K, Irie A, Lertwattanasakul N, Sootsuwan K, Thanonkeo P, Yamada M. Physiological importance of cytochrome c peroxidase in ethanologenic thermotolerant Zymomonas mobilis. J Mol Microbiol Biotechnol. 2011;20(2):70-82.

87. Hayashi T, Kato T, Watakabe S, Song W, Aikawa S, Furukawa K. The respiratory chain provides salt stress tolerance by maintaining a low NADH/ NAD+ ratio in Zymomonas mobilis. Microbiology. 2015;161(12):2384-94.

88. Franden MA, Pienkos PT, Zhang M. Development of a high-throughput method to evaluate the impact of inhibitory compounds from lignocellulosic hydrolysates on the growth of Zymomonas mobilis. J Biotechnol. 2009;144(4):259-67.

89. Franden MA, Pilath HM, Mohagheghi A, Pienkos PT, Zhang M. Inhibition of growth of Zymomonas mobilis by model compounds found in lignocellulosic hydrolysates. Biotechnol Biofuels. 2013;6(1):99.

90. Kerr AL, Jeon YJ, Svenson CJ, Rogers PL, Neilan BA. DNA restrictionmodification systems in the ethanologen, Zymomonas mobilis ZM4. Appl Microbiol Biotechnol. 2011;89(3):761-9.

\section{Submit your next manuscript to BioMed Central and we will help you at every step:}

- We accept pre-submission inquiries

- Our selector tool helps you to find the most relevant journal

- We provide round the clock customer support

- Convenient online submission

- Thorough peer review

- Inclusion in PubMed and all major indexing services

- Maximum visibility for your research

Submit your manuscript at www.biomedcentral.com/submit
BioMed Central 